\title{
LIMPIEZA Y NOBLEZA EN LAS CIUDADES DE CASTILLA: PRETENSIONES Y CONSECUCIÓN DEL ESTATUTO POR PARTE DE MURCIA (1560-1751)
}

\author{
Juan HERNÁNDEZ FRANCO \\ Universidad de Murcia
}

\begin{abstract}
Resumen
La transformación del concejo-comunidad en concejo-ciudad y la consecuente restricción del gobierno urbano en manos de una minoría va acompañada en Castilla del establecimiento por parte de las ciudades (tras concesión regia) de estatutos. Inicialmente de limpieza (siglo XV) y posteriormente (siglos XVI-XVII) de nobleza y limpieza, que permitían seleccionar el acceso de familias a los oficios urbanos. En teoría los estatutos modelan un tipo antropológico caracterizado por su identificación con valores nobiliarios y con un origen cristiano viejo. Y estos estatutos urbanos, desde que son establecidos por vez primera en Toledo el año 1568, no sólo sirvieron a las ciudades que los instituyen para regular las calidades de sus regidores, sino también y a la vez para conseguir un honor social colectivo - del que se benefician sus componentes-. En concreto la ciudad de Murcia, desde fecha tempranas (156) intenta que la Monarquía apruebe su petición de estatuto. Lo consigue casi dos siglos después (1751). Entonces, el estatuto, más que probar el origen limpio de los regidores, homologa a la ciudad con otras importantes ciudades castellanas - las de voto en Cortes- que lo poseen con anterioridad y lo habían convertido en un símbolo de distinción, y sirve para sancionar corporativamente el carácter nobiliario de la oligarquía local, dueña a su vez de los oficios municipales.
\end{abstract}

\begin{abstract}
The transformation of the community council into the city council, and the subsequent restriction of urban government to a small minority of the people, was accompanied in Castille by the setting up of statutes by the cities with royal permission. These statutes were related initially to purity of blood line (in the 15 th century) and later, in the 16 th and 17 th centuries, to both purity of blook line and nobility, allowing selection to be made with regard to which families could hold office in the urban administration. Theoretically, the statutes follow an anthropological model, characterised by their identification with the values of nobility and of Ancient Christian origin. Furthermore, from the moment they were first established in Toledo in the year 1568, they were useful to the cities
\end{abstract}


which established them not only in order to control the quality of their aldermen, but also in order to create a kind of collective social honour from which the members of local government would benefit. The city of Murcia tried to gain royal approval for its statute from an early date (1560). This approval was finally received two centuries later, in 1751. By this time, rather than proving the sound background of the aldermen, the statute put the city on a similar plane to other important Castilian cities: those with the right to vote in parliament. These cities already had their own statutes and had converted them into a symbol of distinction, sanctioning the corporate nobility of the local oligarchy, which in turn controlled all official municipal posts.

Sin lugar a dudas, durante el siglo XV se producen en el municipio castellano importantes transformaciones.Tales transformaciones marcan las señas de identidad de la institución en los cuatro siglos venideros, hasta que el gobierno municipal sea sometido a una auténtica revolución en el siglo XIX.

Las variaciones trajeron, entre otras novedades el cierre social de los concejos, su oligarquización y medios legales para llevarlo a la práctica. La clausura de los concejos comenzó al extenderse la posibilidad de renunciar el oficio de regidor durante el siglo XV, y continuó con más visos de efectividad en los tiempos venideros cuando pudo transmitirse como si de un bien particular se tratara (aunque el cargo siempre perteneció a la corona, pues no hizo venta legal del mismo, en todo caso, gracia o merced a cambio de un donativo económico o de un servicio). La consecuencia fue la perpetuación y continuidad de los empleos en un reducido número de familias, y la gobernación de los concejos conforme a los intereses de una minoría, por cierto cada vez más poderosa y principal '.

Dentro de este proceso de cierre y oligarquización de los concejos castellanos, el concejo de Toledo fue la primera institución de Castilla, el año 1449, que estableció una vía para estatuir (término definido por Sebastián de Covarrubias ${ }^{2}$ con medio para determinar, ordenar o establecer) su composición. Formalizó condiciones e interdicciones para excluir a integrantes de un grupo social con medios para entrar a formar parte del regimiento y tener parte activa en la toma de decisiones: los conversos. Fue el medio para frenar el acceso de miembros de importantes y anteriores familias judías, que disputaban el poder local a familias principales y cristianas viejas. Su pasado, su herencia cultural, repleta de rasgos étnicos y de comportamiento que les diferenciaban de los cristianos viejos, constituía su talón de aquiles; más aún, cuando a pesar de haber recibido el bautismo, se les había situado bajo la sospecha de la herejía y se les volvía a vincular con los judíos. En consecuencia y tal como les sucedía a éstos, a los nuevos cristianos también se les tuvo legalmente por «infames, inhábiles, incapa-

1. F. TOMÁS Y VALIENTE: «Origen bajomedieval de la patrimonialización y la enajenación de oficios públicos en Castilla», en Acta del I Symposium de Historia de la Administración. Madrid, 1970. pp.125159; y «Las ventas de oficios de regidores y la formación de las oligarquías urbanas en Castilla (siglos XVI-XVIII)», Historia, Instituciones, Documentos, $\mathrm{n}^{\circ} 2$ (1975), pp. 525-547.

2. Tesoro de la lengua, 1611 (edición 1993), p. 564. 
ces e indignos por haber todo oficio y beneficio público y privado en la dicha ciudad de Toledo y en su tierra, término e jurisdicción»? ${ }^{3}$.

A partir de entonces, bastantes instituciones principales, haciendo uso de la autonomía con la que contaban, instauran medios de selección que favorecen el acceso de cristianos viejos destacados a sus beneficios o empleos. Se convierten en instituciones de estatuto, lo que además les confirió un grado de honor y prestigio superior a las que no lo poseían ${ }^{4}$.

La implantación de estatutos por parte de instituciones en el siglo que sigue a la promulgación de la Sentencia-Estatuto de Toledo fue más intensa e importante entre los cabildos catedralicios, las órdenes religiosas, los colegios mayores de Castilla y algunas cofradías. No es hasta la sexta década del quinientos, en plenos tiempos recios, cuando el establecimiento de estatutos comienza a ser decidido por los concejos nuevamente.

Los motivos continuaban siendo similares a los que impulsaron al alcalde mayor de Toledo, Pedro Sarmiento, y a las familias viejas de Toledo a establecer el primer estatuto de limpieza de sangre. En Castilla, junto a viejos y distinguidos linajes cristianos viejos, en competencia con ellos, tomando parte en un poder aún efectivo de cara al gobierno de la comunidad baja, estaban los «empinados» conversos. Habían aprovechado los servicios a la corona $y$, sobre todo, las dificultades financieras de la Monarquía a partir del año 1543 y la correspondiente venta de oficios para allegar recursos, para hacerse con oficios concejiles y hacer sentir su peso y propósitos en alguno de los bandos que se habían ido formando en las ciudades de Castilla ${ }^{5}$. Los integrantes del otro bando, ante la competencia que efectuaba la fracción proconversa en el gobierno municipal -y ejemplos de ello encontramos en Sevilla, Toledo, Córdoba, Badajoz, Ciudad Real, Murcia, Lorca, Daimiel, Palencia...-, no dudaron en hacer recaer sobre sus rivales políticos, sin distinción de persona, el delito más aberrante de la época: la herejía -condenada tanto por las leyes religiosas como por las civiles- El estigma de la sangre impura y manchada, el vicio de origen, se constituía una herencia imperecedera. El infortunado legado parecía estar inserto en la memoria colectiva castellana y fue aventado por las principales familias cristianas viejas de varias ciudades, que volvieron a considerar al converso legalmente inhábil e incapaz para desempeñar oficios públicos en sus regimientos, aunque esto no fuese conforme a la ley .

3. Información sobre los precedentes de la sentencia-estatuto, su contenido y las controversias que desata su aplicación, pueden verse entre otros, en E. BENITO RUANO: Los orígenes del problema converso, Barcelona, 1967, pp. 41-83, A. SICROFF: Los estatutos de limpieza de sangre. Controversias entre los siglos XV y XVIII, Madrid, 1985, pp. 51-56, F. MÁRQUEZ VILLANUEVA: «Conversos y cargos concejiles en el siglo XV», en Revista Archivos, Bibliotecas y Museos, $\mathrm{n}^{\circ} 63$ (1957), pp. 503-540, N. ROUND: «La rebelión de 1449», Archivum, n 16 (1966), y J. CONTRERAS: «Hipótesis y reflexiones: la minoría judeoconversa en la historia de España», en Mentalidad e ideología en el Antiguo Régimen (Edc. L. ÁLVAREZ SANTALÓ y C. M. CREMADES GRIÑÁN), Murcia, 1993, pp. 43-47.

4. B. CUART: Colegiales mayores y limpieza de sangre durante la Edad Moderna, Salamanca, 1991, passim.

5. J. CONTRERAS: «Criptojudaísmo en la España Moderna. Clientelismo y linaje», Areas, $N^{\circ} 9$ (1988), pp. $77-100$.

6. Señaló a finales de siglo Castillo de Bobadilla, que por disposición real solo quedaban excluidos los descendientes de conversos que hubieran sido penitenciados por el Santo Oficio y los descendientes de 
El año 1566, nuevamente fue Toledo la primera en instaurar el estatuto. Lo hizo con claros propósitos de selección-exclusión social. Para ocupar oficio en el banco de los regidores caballeros era necesario ser hijosdalgo de sangre, y la condición de hidalgo o, por lo menos, la limpieza para sentarse en el de los ciudadanos ${ }^{7}$. También el año 1566 estableció estatuto el concejo de Sevilla, y dos años después el de Córdoba; en éste era preciso ser hijosdalgo de sangre y no haber ejercido oficios viles durante las dos últimas generaciones familiares para poder ser veinticuatro ${ }^{8}$. Igualmente y continuando con las peticiones -en concreto la LIII y la LXXXVI- efectuadas en las cortes de Madrid del año 1551, se enfatiza sobre que no se concediesen habilitaciones para ser regidores a hijos y nietos de condenados por el Santo Oficio -obtenidas porque semejantes personas son «ricas» y mediante servicios a la corona logran rehabilitarse- y en cuanto a que los hidalgos tengan la mitad de los oficios que se proveen en los pueblos"; en las celebradas el año 1570, las ciudades con voto en cortes solicitaron al monarca que a sus regimientos solo accedieran hidalgos de sangre ${ }^{10}$. En esta ultima petición, que no fue atendida por Felipe II, y de forma similar a lo que también se aprecia en los estatutos implantados, no se focaliza la exclusión únicamente en el converso; comienza a centrarse asimismo en los miembros de grupos urbanos sin privilegios nobiliarios y sobre quienes efectúan profesiones mecánicas.

Tiempos, en definitiva, caracterizados en buena parte de los concejos de Castilla por la discriminación y exclusión de los conversos, y por iguales actitudes ante los que procedían de los sectores ciudadanos. En definitiva, pues es lo que se perseguía por parte de sus componentes, por su hidalguización o, para ser más exactos y poder incluir en estas circunstancias históricas a los tiempos venideros, por su elitización. Concretemos y hagámoslo en términos de la época, de exclusivo -en teoría- acceso a los bancos concejiles de los poderosos, de los principales, de la gentes de lustre de las ciudades y pueblos, identificados plenamente con los principios jerarquizadores y distinguidos de la cultura privilegiada.

$Y$ con estos hechos sociales que venimos describiendo, hay que poner en relación al concejo de Murcia. Con lo que nos encontraremos en las páginas siguientes será con el intento de establecer estatuto el año 1560, incluso antes que Toledo, y la denegación del privilegio por parte de la corona, hasta que finalmente acceda casi dos siglos después -el año 1751-. La consecuencia del estatuto no posee como fin único

éstos por espacio de dos generaciones por linea masculina y una por femenina, y los recién convertidos (Política para corregidores y señores de vasallos, reimpresión. Madrid. 1978, libro III, capítulo VIII)

7. El estatuto, su contenido y cuestiones que acompañan a su puesta en funcionamiento es tratado entre otros por E. LORENTE TOLEDO: Gobernación y administración de la ciudad de Toledo y su término en la segunda mitad del siglo XVI, Toledo, 1982, pp. 123-126, y L. MARTZ: «Pure blood statutes in sixteenth-century Toledo: Implementation as opposed to adoption», Sefarad, LIV (1994), Fasc. 1, pp. $83-108$.

8. J. M. de BERNARDO ARES: «Gobierno municipal y violencia social en Córdoba durante el siglo XVII», Axerquia, n I (1980), p. 22.

9. Cortes de los antiguos Reinos de León y de Castilla, Tomo IV, Madrid, 1882, pp. 523 y 537

10. B. GONZÁLEZ ALONSO: Sobre el Estado y la administración de la Corona de Castilla en el Antiguo Régimen, Madrid, 1981, p. 76. 
la regulación de las calidades que deben tener los «señores Murcia». Junto a ello, y quizás más importante, la pretensión de convertir a la ciudad de Murcia en ciudad de estatuto, distinción u honor concedido a las principales ciudades con voto en cortes, y la aspiración de su oligarquizado concejo de contar con una prueba de su adscripción a los valores hidalgos. A la postre, para el regimiento como corporación y para los regidores como componentes del mismo, las señas de identidad de nobleza y de limpie$\mathrm{za}$, resultaban calidades positivas, honoríficas y homologadoras -institucionalmente para la corporación, socialmente para los regidores-.

\section{1. «ORDENANZA SOBRE QUE NO HAYA OFICIO DE AYUNTAMIENTO EN PERSONA QUE FUERE CONFESO»}

La suplica que efectuó el ayuntamiento de Murcia al rey Felipe II el 20 de Julio de 1560 para que confirmara la ordenanza concerniente a que ningún oficio municipal fuera ocupado por confeso tenía unas profundas raíces. Los regidores no estimaron oportuno su exposición. Bastaba con la realidad más próxima: «de dos años a esta parte se a visto por esperiençia en esta cibdad que todos los regidores e jurados que tenían parte de confesos e no heran cristianos viejos an sido presos por el Santo Oficio, e cada día van prendiendo ansi de los del ayuntamiento que tiene la tal parte como de fuera del que pretenden entrar... ${ }^{\prime \prime}$.

Para qué remontarse a pruebas anteriores para conseguir la exclusión del concejo de un grupo de conversos que desde el siglo anterior habían querido asimilarse a lo más granado de la sociedad murciana obteniendo empleos municipales. No hizo falta referir que Murcia había sido durante el siglo XV una de las aljamas más importantes de Castilla y que tras la conversión de una parte de sus integrantes algunos judaizaron ${ }^{12}$; que concretamente el año 1488 se creó un distrito inquisitorial para perseguir a dudosos conversos ${ }^{13}$; que el cabildo-catedral de Murcia fue el tercer cabildo de Castilla en establecer estatuto de limpieza el año 1517, precisamente para evitar que accedieran los manchados ${ }^{14}$; o que antes de 1543 (Laras, Bernal, Bustamante...) y también a partir de esta fecha tan significativa para el acrecentamiento del número de regidurías de los concejos castellanos, mediante ventas (Juan Valibrera, Ximen Pérez de Valibrera, Luís de Ceballos...) en los dos bancos que existían en el ayuntamiento de Murcia se estaban sentando cristianos nuevos.

Bastaban con las pruebas más inmediatas, ligadas al descubrimiento de una comunidad judaica en Murcia el año $1558^{15}$, y sobre todo la contundencia con que la In-

11. Archivo Municipal Murcia (A.M.M.), Acta Capitular (A. C.) 1560, sesión (s.) 20-julio-1560.

Previamente ya había tratado sobre el estatuto F. CHACÓN JIMÉNEZ: Murcia en la centuria del quinientos, Murcia, 1979, pp. 448.

12. J. TORRES FONTES: «La judería murciana en época de los Reyes Católicos», en Espacio, tiempo y forma, serie III, Historia Medieval, Tomo VI (1993), pp. 177-218.

13. J. CONTRERAS y J. P. DEDIEU: «Geografía de la Inquisición española. La formación de los distritos, 1470-1820», Hispania, $\mathrm{n}^{\circ} 144$ (1980), pp. 79-81; y J. TORRES FONTES: Estampas medievales, Murcia, 1988, pp. 506-513.

14. J. HERNÁNDEZ FRANCO: Cultura y limpieza de sangre en la España Modema, Murcia, 1996, pp. 39-41.

15. CONTRERAS: Sotos contra Riquelmes, Madrid, 1992, pp. 113-185. 
quisición estaba probando por medios harto dudosos -en lo que tenía bastante que ver las insinuaciones del bando local al que no pertenecían- la persistencia de una conducta mosaica entre los regidores y jurados conversos que tenían oficio en el concejo y que acabó con bastante de ellos en la hoguera ${ }^{16}$, para justificar el documento legal mediante el que el regimiento de Murcia excluía de sus cargos a los confesos y protegía su honor y distinción. Una ciudad con la condición de «muy noble», no podía ver manchado su identidad por el comportamiento herético con que se relacionó a todos los regidores de ascendencia judía. Sus regidores y demás oficios -hasta el de portero- tenían que ser limpios y cristianos viejos por ambas líneas por espacio de cuatro generaciones.

Para que la ordenanza tuviera condición de ley el regimiento hizo la correspondiente suplica al rey, como tutor que era de las ciudades ${ }^{17}$. Sin embargo el monarca no accedió. El tutor no dió su aprobación a la petición de la tutorada, y Murcia no pudo disponer de estatuto, a pesar de que el problema y motivo por el que hacía la solicitud no eran diferentes a los que seis años después expondrán los regimientos de Toledo y Sevilla y ocho años más tarde el de Córdoba.

De momento la ordenanza quedaba en suspenso y no será hasta setenta y cinco años después cuando la ciudad vuelva a solicitarla al monarca. Aunque ahora en un marco distinto. No persigue la selección racial sino la selección social.

\section{2. «ESTATUTO Y ORDENANZA QUE DE AQUI ADELANTE NINGUNA PERSONA PUEDA SER ADMITIDA A ESTE AYUNTAMIENTO POR REXIDORES QUE NO SEA CAVALLERO HIXODALGO Y QUE NO AYA TENIDO NINGUN OFICIO MECANICO»}

Esos pequeños espacios jurisdiccionales que son las ciudades, miniaturas - en comparación con el tamaño y poder que ha adquirido la forma de Estado que se está desarrollando- como ha señalado A. M. Hespanha, continúan solicitando a los monarcas a lo largo de la segunda mitad del siglo XVI, del XVII y del XVIII estatutos de calidades mediante los que regular la admisión en los oficios municipales. La ciudad de Murcia será una de las que lo vuelva a solicitar el 30 de Agosto de 1637.

Efectúa su petición a la Monarquía situándose como corporación dentro del marco o ambiente cultural y social que había establecido la minoría social, los privilegiados, los poderosos para ser más exactos - por cuanto nos encontramos en el mundo urbano-. Murcia y las restantes ciudades peticionarias adaptan el estatuto a los hechos sociales que quieren legalizar, que quieren ordenar sus oligarquías, con el fin de reservarse a si mismas el acceso a los oficios relevantes de los municipios castellanos.

Se han producido a partir de 1580 aproximadamente, circunstancias que los poderosos que gobiernan los concejos quieren recoger y regular en los estatutos, bien

16. En el auto de te celebrado el 8 de Septiembre de 1560 fueron relajados los regidores Juan de Valibrera y Alvaro de Lara, y en el celebrado el 15 de Marzo de 1562, lo serían los jurados Pedro Fernández de Santafé y Pablo de Aylión, y el mayordomo Juan de León (J. C. DOMÍNGUEZ NAFRÍA: La Inquisición de Murcia en el siglo XVI: el licenciado Cascales, Murcia, 1991, pp. 112-121.

17. J. 1. FORTEA PÉREZ: «Poder real y poder municipal en Castilla en el siglo XVI», R. PASTOR et alii: Estructuras y formas de poder en la historia, Salamanca, 1992, p. 127. 
para eliminar hechos que pueden serles perjudiciales, bien para potenciar otros que les resultan beneficiosos. Por un lado, no ha cesado el acrecentamiento de oficios municipales iniciado a mitad del siglo XVI, y tal situación ha permitido procesos de movilidad social (rápidos y socialmente perceptibles más que masivos) que han permitido el acceso a las oligarquías de más personas y de personas que no tienen un modo de vida, una identidad social, una trayectoria familiar, similar a la de los que con anterioridad integraban la corporación municipal. Por otra parte, los componentes más antiguos de los concejos, tras haber logrado bastantes de ellos mediante renuncias y patrimonialización de oficios su práctica propiedad, y precisamente para resaltar su identidad social distinguida y la de la propia corporación son partidarios de la «aristocratización ${ }^{18}$ de la institución local o, cuando menos, de su oligarquización -que supone colocar el poder local en manos de una minoría dirigente ${ }^{19}$ con tendencia a la reproducción-. Y para este fin de reservar sólo a nobles los puesto concejiles o, al menos a personas asimiladas a valores hidalgos y convencidas de que el poder local sólo debe ser ejercido por un estrato dirigente, los concejos con mayor peso político del reino de Castilla solicitan a la Monarquía la aprobación de estatutos en los que la calidad de la sangre noble, del origen noble, de la familia de casa y linaje inmemorial, de la cuna ${ }^{20}$, sea el fundamento, la sustancia o el referente primordial y necesario para ingresar.

Este cambio que han introducido los poderosos para continuar con su monopolio sobre el poder local, supone avanzar de la discriminación respecto a los conversos hasta la discriminación hacia una amplia mayoría de cristianos viejos de condición social no nobiliaria o próxima a los que Cervantes llamaba «ganapanes». Y de este propósito deja constancia el estatuto con más transcendencia de los aprobados por la Monarquía durante el siglo XVII: el concedido al concejo de Madrid. Le fue otorgado por Felipe IIl el año 1603. Su principal estudioso ha dicho que contribuyó a lograr la hegemonía nobiliaria en la villa, a reforzar la imagen identitaria de los poderosos y la solidaridad ante los propósitos de otros grupos, y aunque no impidió el acceso a burgueses y ciudadanos, si que los discriminó como grupo ${ }^{21}$.

Teniendo presente la ideología predominante en los principales concejos de Castilla y que sus elites podían legalizarla mediante la aprobación por parte del monarca del correspondiente estatuto, los regidores de la ciudad de Murcia, representantes de un gobierno urbano oligarquizado y con claros síntomas de cierre -más que aristocratizado $^{22}$-, el 30 de Agosto de 1636 solicitaron a su majestad que confirmara la orde-

18. A. DOMÍNGUEZ ORTIZ: Las clases privilegiadas en la España del Antiguo Régimen, Madrid, 1973, pp. 124-127.

19. J. A. MARAVALL: Poder, honor y elites en el siglo XVII, Madrid, 1984, pp. 149 y sgts.

20. Entre otros muchos trabajos del autor, sin duda donde primeramente trató sobre esta idea J. I. Gutiérrez Nieto, fue «Estructura castizo-estamental de la sociedad castellana en el siglo XVI», Hispania, $\mathrm{n}^{\circ}$ 125 (1973), pp. 539 y sgts.

21. M. HERNÁNDEZ: «EI cierre de las oligarquías urbanas en la Castilla Moderna: el estatuto del concejo de Madrid (1603)», en Revista Intemacional de Sociología, $\mathrm{n}^{\circ} 45-1$ (1987), y «Oligarquía hidalga: el "estatuto" del concejo de Madrid», en Villa de Madrid, n' 108 (1992), pp. 7-12.

22. J. J. RUIZ IBÁÑEZ: Las dos caras de Jano. Monarquia, ciudadano e individuo. Murcia, 1588-1648. Murcia, 1995, pp. 155 y sgts. 
nanza y estatuto que impedía admitir por regidores en su ayuntamiento a personas que no proviniesen --al menos durante dos generaciones- de familias hidalgas.

Las causas de la interdicción y en consecuencia la implantación de la identidad nobiliaria que quería imponer el cabildo murciano, se encuentran en el conocimiento de la reciente renuncia (12 de Agosto) que había efectuado Bernardo Salafranca del oficio de regidor del que era propietario en Baltasar Espín. Consideraban los capitulares que es una persona «en quien no concurren las calidades que para ser rexidor son necesarias por quanto a exercido oficio de sastre y calcetero». Por este defecto mecánico, mucho más extendido que la mancha étnica, e igualmente peligroso por cuanto subvertía el orden social ${ }^{23}$ y amenazaba la imagen identitaria del grupo, la ciudad de Murcia en pleno, sin distinción de bandos y recordando los vetos impuestos a aspirantes a regidurías en similares condiciones, contradijo la renuncia y rechazo la admisión de Baltasar Espín. El voto -y su correspondiente explicación- de un viejo munícipe murciano, de reconocida identidad nobiliar, don Antonio Fontes de Albornoz Riquelme ${ }^{24}$, fue contundente en la sesión del 12 de Agosto, al decir a sus compañeros que «no es bien que ombre de tan baxo nacimiento tenga tal rezevimiento ${ }^{25}$.

Como ya se ha indicado, el 30 de Agosto, el concejo, corporativamente, propuso la ordenanza-estatuto. Previamente aparecen las dos razones que la motivan. En primer lugar y en sintonía con otros grupos municipales dirigentes, señalan su nivel de oligarquización; incluso para ser más respetuosos con el documento, su inveterada hidalguía: «los dichos oficios an sido como es notorio de la gente más noble y calificada desta ciudad». Y ese estado social global del concejo lo manifiestan a través de un discurso sobre la sangre de índole estrictamente social y favorable a sus propósitos de reserva; mediante el mismo consideran la sangre alta y noble como la más adecuada para ejercer de forma eficaz oficios que conllevan el servicio al monarca. En segundo lugar, y tal como ocurrió en tantas otras instituciones de relieve de la España Moderna y ha señalado B. Cuart, se encuentra el propósito del concejo murciano de quedar homologado con otras instituciones de similar o superior rango. En el caso que nos ocupa, se realiza a "ymitación de otras ciudades cavezas del rreino que tienen estatutos de las calidades que an de tener los cavalleros rexidores de su ayuntamiento». A continuación se encuentra la norma reguladora del acceso al ayuntamiento, y la petición al monarca para que valide el estatuto. Su majestad no escuchó la suplica.

Por tanto, el interés corporativo del oligarquizado concejo de Murcia para conseguir estatuto de nobleza, a diferencia de lo que ocurre un año después con la petición del cabildo de Madrid a Felipe IV para que ratifique su estatuto de nobleza y limpie$z a$, no es satisfecha. Durante el reinado de este monarca la insatisfacción de no conseguir estatuto no le cupo únicamente al concejo murciano. Tampoco fue receptivo a la petición efectuada por los procuradores de la ciudades en Cortes el año 1651; no ac-

23. J. A. MARAVALL: Poder, honor..., pp. 130-131.

24. Precisamente ese año se publicaba el Discurso Historical Genealógico de la Noble Familia de los Fontes de Albornoz (edición a cargo de J. Torres Fontes, Murcia, 1990), dónde se prueba la calidad "nobilisima» de la familia.

25. A.M.M., A. C.1636-37, s. 12-agosto- 1636. 
cedió a su solicitud de que los regidores y jurados de las dieciocho ciudades hubieran de tener la calidad de hijosdalgo de sangre ${ }^{26}$.

El posible motivo de tal actitud de la Monarquía puede tener relación, por un lado, con la pérdida por parte de las ciudades con representación en Cortes, las llamadas «cabezas del reino», del voto consultivo y la introducción el año 1632 del llamado voto decisivo -suponía para las oligarquías locales la perdida de un importante elemento de negociación y en cambio abría el camino a un poder absoluto no condicionado por ellas ${ }^{27}$-. De otro lado, también debe tenerse en cuenta, que una de las vías empleadas por la Monarquía Absoluta para hacer frente a las necesidades económicas que le originó su política de reputación y el correspondiente esfuerzo militar, fue la venta de oficios municipales, pues eran de su propiedad; los otorgó no siempre a «servidores» de condición hidalga, sino también a personas de calidad plebeya que habían maquillado su origen y que venían colaborando financieramente con ella, o bien estaban integradas en redes de poder afectas a sus propuestas y peticiones -a veces inasumibles para los regidores partidarios de una mayor autonomía municipal-.

Algunas de estas circunstancias parecen adivinarse en la no concesión de la ordenanza-estatuto que había solicitado el concejo de Murcia; así como también en los hechos que acompañan a la admisión en el colegio murciano de la persona que había provocado la petición de la norma de reserva nobiliar.

Trataremos de situar las cuestiones que planteamos en el tiempo. Los años 16261627, coincidiendo con el cambio de los genoveses por los portugueses como financieros de la Monarquía y sobre todo con la ruina de quien hasta entonces había manejado las finanzas reales en Murcia, el regidor Miguel Pérez de Villaseñor (Tesorero de alcabalas, millones y servicios), dió lugar a que de éstas se hiciera cargo la poderosa familia Salafranca. Al mismo tiempo un destacado miembro de ella, Bernardino de Salafranca, consiguió oficio de regidor (exactamente a partir del año 1628). Fue él quien entre julio y agosto de 1636 renunció su oficio en Baltasar Espín, a quien con molicie los regidores presentaban como «sastre y calcetero», y no parecían acordarse que el año 1634 había sido tesorero de rentas reales en Murcia. Nuevamente lo intentó ser el año 1637. No lo consiguió inicialmente, pero y esto es lo que nos interesa resaltar, contó con el voto de regidores próximos al bando realista; entre ellos se encontraba Ginés de Rocamora, quien al justificar el sentido de su voto sostuvo lo «bien que administró en sus tiempo las rentas ${ }^{28}$. Cuestión que nos hace pensar en el citado Baltasar, como miembro de una red de poder o, cuando menos, de un bando local bien relacionado con la corte, y bien visto por Olivares y sus ministros debido a su eficacia como agente recaudador; así como considerarle una persona próxima a la

26. B. GONZÁLEZ ALONSO: Sobre el Estado y la administración..., p. 74.

27. CH. JAGO: «Habsburg Absolutisme and the Cortes of Castille», American Historical Review, 86, núm. 2, 1981, pp. 24-43; I. A. A. THOMPSON: «Crown and Cortes in Castille, 1590-1665», Parliaments, States and Representation, vol 2, núm, 1984, pp. 29-45; y en concreto para Murcia la obras de F.J. GUILLAMÓN-J.J. RUIZ IBÁÑEZ- J.J. GARCÍA-HOURCADE: La corona y los representantes del Reino de Murcia (1590-1640), Murcia, 1996, p. 14 y 35-42.

28. A.M.M., A. C. 1636-37, s. 24-diciembre-1636. 
burguesía de negocios que el valido intentaba dignificar y promover como contrapeso de las viejas oligarquías castellanas.

Dejemos aquí esta cuestión y sigamos el camino por el que finalmente accederá Espín a su oficio de regidor, no sin antes haber obtenido ejecutoria de hidalguía -cumpliendo, por tanto, el requisito que quería imponer la oligarquía local, aunque a ésta no le fuese otorgada la merced del estatuto-. Los hechos que se expondrán inmediatamente, parecen guardar relación mediante el común denominador de las necesidades y urgencias de la Monarquía y los servicios prestados por una clientela a la que se premia con la entrada en la casi inaccesible oligarquía murciana; lo que a la vez supone no escuchar las pretensiones de la última de cierre social hermético.

El oficio de Bernardino de Salafranca, número veinte y siete de los cuarenta y uno que tenía el concejo de Murcia, pasó por breve espacio de tiempo a Luís Salad Anduga (20-Septiembre-1636 a 25 de noviembre de ese mismo año). Antes de que acabara el año 1636 lo renunció en Don Francisco de Verastegui Lisón y Carrillo Manuel. Tampoco conservó mucho el oficio el último, y el 21 de Julio de 1637, después de problemas con sus restantes compañeros de cabildo -no sabemos bien si por éste o por otro oficio del que podía ser propietario- a causa de las preeminencias que le suponían haber incorporado al título de regidor el de alcalde mayor tras su correspondiente compra a la Monarquía, hizo renuncia (fuera de Murcia) del oficio número veinte y siete y solicitó al monarca que pasara a la persona de Baltasar de Espín. Y así ocurrió. La real carta indicaba que «nos acatando vuestra sufizienzia y abilidad y los servixios que nos aveis hecho... es nuestra voluntad que agora y de aqui adelante seais nuestro regidor de la dicha ciudad de Murcia»" ${ }^{29}$.

El 22 de Agosto de 1637, a penas un año después de que fuera vetado por los poderosos murcianos por su condición social anómica, por su condición de hombre llano, relacionado con oficios mecánicos, manchado por tanto por la vileza, y carente del honor, prestigio y distinción de los selectos, se presentó Baltasar Espín ante el concejo de Murcia con su merced de oficio real. La ciudad acató y cumplió la orden regia, pero antes de obedecerla paso a votar la admisión. De los diecisiete regidores presentes, trece aprueban que «se reciba como Su Majestad lo manda». Sin embargo dos solicitaron que en un próximo concejo se revocara la contradicción que pesaba sobre Espín y que le impedía ser regidor; y otro dos, pertenecientes al sector más radical del bando municipalista, pedían al monarca que suspendiera la concesión del título de regidor otorgado a Espín ${ }^{30}$.

Definitivamente Baltasar Espín, vecino y natural de Murcia, calcetero, sastre, tesorero y receptor de rentas reales, y algo que tampoco sabíamos hasta el momento: familiar del Santo Oficio, fue recibido como regidor en un concejo que quería, a toda costa, convertirse en una corporación con estatuto de nobleza.

Sin lugar a dudas, y lo prueba su calidad de familiar de la Inquisición, Baltasar era un cristiano viejo. Pero a diferencia de hacía setenta y ocho años, la mancha que en esos momentos estigmatizaba la minoría de poder castellana no era la étnica, sino

29. A.M.M., Cartas Reales 1636-1640, Madrid, 3-agosto-1637.

30. A.M.M., A. C. $1637-38$, s. 22-agosto-1637. 
la popular vileza, y esa vileza sólo la podía difuminar con una provisión de hidalguía otorgada por el correspondiente tribunal real. Procediendo como hicieron otros casteIlanos viejos que suspiraban por la condición hidalga, Baltasar consiguió su ejecutoria de hidalguía y quedó integrado dentro del grupo de poder que aspiraba a reservar para sus selectos y poderosos integrantes el poder municipal en la Castilla del siglo XVII. Espín no estaba dispuesto a que un origen plebeyo o, cuando menos una nobleza dormida o perdida, le dificultara la admisión ${ }^{31}$, y sabiendo ya la opinión corporativa de los regidores murcianos respecto a las calidades que debían tener quienes accedieran a la institución, litigó en la Chancillería de Granada su nobleza.

El 18 de Agosto de 1636 comenzaron en Murcia las averiguaciones sobre el origen y naturalezas del citado Espín. Los testigos, casi de menos condición social que él -clérigos, un labrador, un tejedor, un sastre y un solo hidalgo-, declararon que era «hixodalgo notorio, hijo y nieto y descendiente de tales» y que disfrutaba de la preeminencias, privilegios y exenciones de los hidalgos de Murcia, que no había ejercido oficios viles, y sobre todo, pues era lo único cierto, que era limpio. Tras el arsenal de pruebas a su favor que produjo la instrucción del informe de hidalguía, la Chancillería falló afirmativamente y lo reconoció como hidalgo. Y con la citada resolución se presentó Espín en la sesión celebrada por el concejo de Murcia el 18 de Julio de 1637 y solicitó su inclusión en el estado noble y como corroboración de ello la inserción de su provisión de hidalguía en el libro de Cartas Reales de la ciudad -contenía las anteriores cartas de hidalguía a favor de la oligarquía local-. El 21 de Julio ocurrió la incorporación de su ejecutoria al libro, y como ya sabemos solo transcurrió un mes hasta que el concejo lo reconoció como propietario del oficio número veintisiete. En tan señalado día para la vida personal de Espín, tras haber probado su identidad nobiliaria, el concejo de Murcia abría un portillo por donde le dejaba acceder. El concejo no había logrado de forma manifiesta el estatuto de nobleza, pero latentemente exigía tal condición a sus integrantes.

\section{3. «OS HAGO MERCED A VOS LA DICHA CIUDAD DE MURCIA DE QUE SEAIS DE ESTATUTO DE NOBLEZA»}

Definitivamente, el 21 de Octubre de 1751, en San Lorenzo del Escorial, Fernando VI concedía a Murcia el privilegio de ciudad de estatuto. En un periodo en el que había continuado acrecentándose el carácter aristocrático de las oligarquías urbalnas de Castilla ${ }^{32}$, la ciudad de Murcia se agregaba al ya amplio racimo de ciudades de estatuto. Compartía tan importante honor, entre otras, con Toledo, Sevilla, Córdoba, Madrid, Jaén, Málaga, Burgos, Ubeda, Toro, Jerez, Orense, Zamora, Granada o Salamanca -últimas en obtenerlo a lo largo del reinado de Felipe $\mathrm{V}-$.

31. No podemos afirmar plenamente que Baltasar Espín amañara su origen y lo ennobleciera por medios ilegítimos - «valiendose (como hizieron otros) para esto de escrituras y testigos falsos y de todo arte y maldades»-, pero era una práctica tan extendida en esos momentos para alcanzar la condición de hidalgo, tal como lo denunciaba en un informe fechado el año 1652 un alcalde de la sala de hijosdalgos de la Chancillería de Valladolid (Biblioteca Nacional, Manuscrito 18728), que al menos debemos manifestar nuestras sospechas.

32. A. DOMÍNGUEZ ORTIZ: Sociedad y Estado en el siglo XVIII español, Barcelona, 1976, p. 458. 
La ciudad se hace con esta prerrogativa de estatuto tras haberlo solicitado durante un dilatado periodo de tiempo. No fue la única que tardó tanto en conseguirlo. Granada, ciudad que obtiene el estatuto el año 1739, siguió una trayectoria similar a Murcia. Lo solicitó por vez primera el año 1571 , volvió a repetir la petición los años 1670 y 1694, y no lo poseyó hasta el mencionado año de $1739^{33}$.

Como en anteriores ocasiones se sabía que la consecución del estatuto había que obtenerla en la corte. A la corte le correspondía la concesión de honores y mercedes, pero era el beneficiado quien debía exponer los méritos y servicios que le hacían acreedor del don. La ciudad de Murcia puso al frente de tal objetivo -que no era único, pues se incluyó dentro de un conjunto de solicitudes que efectuaba al monarca y entre las que se encontraban: perdón de los 70000 reales que se adeudaban en concepto del servicio ordinario, nuevo repartimiento general del agua, reconocimiento de todos los privilegios concedidos a la ciudad por parte de Felipe V, privilegio relativo a los fieles ejecutores y aumento de los salarios de los empleados municipales- a un experimentado miembro del cabildo, perteneciente a una de las familias más veteranas y representativas de la oligarquía murciana, don Juan Carrillo, o para ser más exactos Juan Lucas Verastegui, bisnieto de un regidor ya nombrado en este trabajo Francisco Verastegui y Lisón Carrillo Manuel y padre del futuro Marqués del Campi1lo, momento culminante en el ascenso social de una vieja familia murciana que había aspirado a formar parte del estado aristocrático -nada mejor para ello que no olvidar su parentesco con el antiguo y reputado linaje de los Carrillo, muy próximo a los primeros Trastámaras-.

Muy posiblemente desde Abril de 1751, don Juan Carrillo, en compañía del secretario del ayuntamiento Pedro Fajardo, estuvo en Madrid, y entre los diversos asuntos bajo su encargo, tuvo como principal el estatuto; así se reconoció en la sesión celebrada el día 6 de Noviembre de $1751^{34}$, una vez otorgada la gracia por parte del rey Fernando.

Tras presentar la petición de estatuto de nobleza y vista e informada la misma por el Consejo de Castilla los primeros días de Julio de 1751, como señala el propio Juan Carrillo, el camino fue allanado hasta conseguir el citado privilegio, practicando «eficaces diligencias», que consistieron en visitas a influyentes cortesanos, a círculos políticos y a personas influyentes de origen murciano que podían hacer llegar la pretensión de la ciudad al entorno monárquico. El estatuto fue posible por la «poderosa mediación de los ilustrísimos protectores y paisanos y otros señores ministros interesados en favorezer a este ayuntamiento» ${ }^{35}$. En una palabra, por el apoyo de amigos políticos, de redes de poder en las que se insertó y con las que conectó el enviado del concejo murciano. Así se obtuvo la ansiada gracia real, que fue sin duda trabajada, no espontánea, producto de relaciones políticas ${ }^{36}$; gracia aún valiosa y con importancia

33. J. MARINA BARBA: Poder municipal y reforma en Granada durante el siglo XVIII, Granada, 1992, pp. 49.

34. A.M.M., A. C. 1751, s. 13-marzo-1751.

35. A.M.M., A. C. 1752 , s. 4-marzo-1752.

36. A. M. HESPANHA: La gracia del Derecho, Madrid, 1993, pp. 154-156. 
honorífica dentro del ideario de las ciudades hispanas, pues no era concedida a todas ellas -por ejemplo en ese siglo se le volvió a negar a Motril, a Medina del Campo, a Guadix...-.

La fidelidad y las prestaciones efectuadas por parte de la ciudad de Murcia a lo largo de casi cinco siglos, y especialmente -como ocurre con otras ciudades que también obtienen el estatuto de nobleza en el siglo XVIII, casos de Granada y Salamanca ${ }^{37}-$ los «distinguidos servicios» llevados a cabo durante la Guerra de Sucesión a favor de la causa borbónica, tuvieron su retribución el 21 de Octubre del año 1751 mediante la gracia del estatuto de nobleza ${ }^{38}$.

La ciudad de Murcia ya era de las de estatuto. Y muy probablemente para su corporación la circunstancia de disponer de prerrogativa regia que sentenciaba que quienes en el futuro ocuparan oficios de regidor habrían de ser «nobles, hijosdalgos de sangre y no de privilegio ni descendiente de ellos», trascendía el objetivo de reserva de los oficios exclusivamente en personas de la citada condición. Creemos que les proporcionaba algo más. Primeramente, se homologaba con las restantes ciudades cabezas del reino, es decir con las ciudades con voto en Cortes, que era a las que hasta entonces de forma mayoritaria se les había otorgado estatuto. No pudo la ciudad de Murcia contener su inflación de lustre e inmediatamente participó el honor a las ciudades con representación en Cortes, y muy especialmente a las ciudades con estatuto de nobleza y limpieza más distinguido: Toledo, Sevilla y Madrid ${ }^{30}$. En segundo lugar, es cierto que de forma corporativa la ciudad, tras la Guerra de Sucesión, había visto premiada su colaboración con la causa borbónica a través de la entrega de la séptima corona y un corazón con una flor de lis y un león para su escudo de armas, y con la confirmación de sus privilegios; e incluso, a nivel individual, a algunos regidores de la oligarquía (Antonio de Roda y José Puxmarín) les fueron concedidos títulos aristocráticos y signos distintivos de tal rango como llaves de gentilhombre, o bien de su incardinación en la vida cortesana, como eran los oficios de caballerizos. Pero los regidores querían, por encima de todo, algo que corporativamente sancionara su carácter nobiliario, y eso solo lo podía otorgar el estatuto de nobleza -su gran objetivo en las peticiones de mercedes del año 1751-. Era un honor corporativo, que debía tener reconocimiento en toda la Monarquía, desde las primeras personas por debajo del rey: los infantes, hasta el último justicia del reino, incluyendo también los enclaves de jurisdicción señorial, Nadie podría poner en entredicho el carácter nobiliario de los componentes del concejo murciano.

37. J. MARINA BARBA: Poder municipal y reforma en Granada..., pp. 337-343, y J. INFANTES MIGUEL MOTTA: El municipio de Salamanca a finales del Antiguo Régimen. Salamanca, 1984, pp. 317-322.

38. A. M.M., Cartas Reales 1751-1752, San Lorenzo, 21-octubre, 1751. La reproducción íntegra del estatuto puede consultarse en J. GUILLAMÓN ÁLVAREZ y J.J. RUIZ IBÁÑEZ: «Guía de regidores y jurados de Murcia: 1650-1800», en Cuadernos del Seminario Floridablanca, ${ }^{\circ} 3$ (1996), pp. 112-116. Igualmente encontramos referencias al mismo en J. GUILLAMÓN ÁLVAREZ: Regidores de la ciudad de Murcia, Murcia. 1989, pp. 36 y sgts.; y C.M. CREMADES GRIÑ̃́N: Economia y hacienda local del concejo de Murcia en el siglo XVIII (1701-1759), Murcia, 1986, p. 54.

39. A.M.M., A. C. 1752 , s. 15-abril-1752. 
A partir de 1752 y hasta cuando menos el año 1834, las personas que conseguían el título de regidor en el ayuntamiento de Murcia (existen 79 expedientes de nobleza y limpieza relativos a esas fechas) tuvieron que probar la nobleza de su sangre. Más que para una selección efectiva y rigurosa de hidalgos de sangre -pues junto a aristocratas también superaron las pruebas aspirantes de raíces plebeyas y escasa trayectoria nobiliaria ${ }^{\text {t0}}-$, y de forma similar a lo que ocurrió en tantas instituciones que alardeaban de estatuto, tal instrumento lo utilizó la ciudad durante los años que estuvo en vigencia para recordar y poner de manifiesto, mediante el ritual de la información, el privilegio y las calidades nobiliarias que por parte de la corona se habían reconocido a la institución -equiparada desde entonces al resto de las importantes ciudades de estatuto- y para identificar y revestir colectivamente a los regidores de Murcia con el distinguido status.

40. Nada se puede objetar de la nobleza de regidores como Fernando Díaz de Mendora y Valcárcel, a la sazón Conde de Laling y Bazalote, Marqués de Fontanar y de San Mamés, y Grande de España de Primera, así como de bastantes otros que poseían el lustre y condición noble que había alcanzado el concejo de Murcia. Difícilmente se puede sostener lo mismo respecto a Ventura Azcoytia, Mateo Ceballos, Francisco Tomas de Jumilla, Mariano Vázquez, Francisco Mesas..., hombres de raíces plebeyas (A.M.M., Legajo n 7327). 